\title{
MULTILETRAMENTOS E MULTIMODALIDADE NA CARTOGRAFIA ESCOLAR PARA O ENSINO DE GEOGRAFIA: CONSIDERAÇÕES GERAIS
}

\author{
Multiliteracies and multimodality in school cartography for geography education: general \\ considerations
}

\begin{abstract}
Multiletramentos y multimodalidad en la cartografía escolar para la educación en geografía: consideraciones generales
\end{abstract}

\author{
Natália Lampert Batista* \\ Elsbeth Léia Spode Becker** \\ Roberto Cassol*** \\ *Pós-doutoranda em Geografia/UFSM - natilbatista3@gmail.com \\ **Professora do MEHL/UFN -elsbeth.geo@gmail.com \\ *** Professor voluntário do PPGGEO/UFSM - rtocassol@gmail.com
}

Recebido em 04/10/2019. Aceito para publicação em 20/10/2019.

Versão online publicada em 10/11/2019 (http://seer.ufrgs.br/paraonde)

\begin{abstract}
Resumo:
Os mapas são uma importante linguagem do ensino de Geografia que na contemporaneidade estão fortemente entrelaçados aos multiletramentos e a multimodalidade no estudo das diferentes temáticas geográficas. Assim, o presente artigo, fez-se um esboço teórico sobre a temática Cartografia Escolar, multimodalidade e multiletramentos voltados ao ensino de Geografia. O texto auxilia professores e pesquisadores da área na compreensão dos conceitos mencionados e em suas possíveis utilizações no ensino dessa disciplina. Concluiu-se que o ensino de Geografia e a Cartografia Escolar vêm sendo desfiados a compreender e a investigar essas novas formas de representar e de entender o mundo que se configuram no contexto contemporâneo. Para isso, as aulas de Geografia devem trabalhar a representação do espaço geográfico de modo articulado com as múltiplas linguagens, tecnologias e mídias emergentes, no contexto ambiental, social, político, econômico e multicultural que integra a vida em sociedade no século XXI.
\end{abstract}

Palavras-chave: Ensino de Geografia. Cartografia Escolar. Multimodalidade e Multiletramentos.

\begin{abstract}
:
Maps are an important language in the teaching of geography that in contemporary times are strongly intertwined with multiliteracies and multimodality in the study of different geographical themes. Aims in the present article was made a theoretical sketch on the theme School Cartography, multimodality and multiliteracies focused on the teaching of geography. The text assists teachers and researchers in the area in understanding the concepts mentioned and their possible uses in teaching this subject. It was concluded that the teaching of Geography and School Cartography are challenged to understand and investigate these new ways of representing and understanding the world that are configured in the contemporary context. For this, the Geography classes must work the representation of the geographical space in an articulated way with the multiple languages, technologies and emerging media, in the environmental, social, political, economic and multicultural context that integrates life in society in the 21 st century.
\end{abstract}


Key-words: Geography teaching. School Cartography.Multimodality and Multilanguage.

\begin{abstract}
Resumen:
Los mapas son una lenguaje importante en la enseñanza de la geografía que en los tiempos contemporáneos están fuertemente entrelazados con multiletramentos y multimodalidad en el estudio de diferentes temas geográficos. Así, el presente artículo se realizó un bosquejo teórico sobre el tema Cartografía escolar, multimodalidad y multiletramentoscentrados en la enseñanza de la geografía. El texto ayuda a los maestros e investigadores en el área a comprender los conceptos mencionados y sus posibles usos en la enseñanza de esta materia. Se concluyó que la enseñanza de Geografía y Cartografía Escolar tiene el desafío de comprender e investigar estas nuevas formas de representar y comprender el mundo que se configuran en el contexto contemporáneo. Para esto, las clases de Geografía deben trabajar la representación del espacio geográfico de manera articulada con los múltiples idiomas, tecnologías y medios emergentes, en el contexto ambiental, social, político, económico y multicultural que integra la vida en la sociedad en el siglo XXI.
\end{abstract}

Palabras-clave: Geography teaching. School Cartography.Multimodality and Multilanguage.

\title{
1 Introdução
}

O ensino de Geografia contemporâneo se vê desafiado a retornar ao pensamento crítico-reflexivo, buscando aprofundar os saberes e contribuir com o entendimento verdadeiro desta sociedade dinâmica e fluída. Para isso, podem ser utilizadas as linguagens em ascensão desta época, como a Cartografia, para atingir tal objetivo e abordar todas as temáticas inerentes ao espaço geográfico,de modo mais contextualizado e complexo, sejam elas físico-naturais sejam socioeconômicas e políticas.

Neste ínterim, a ciência (técnica e arte) dos mapas se torna muito relevante na contemporaneidade. Converte-se em um objeto de interesse e de curiosidade das diversas gerações e grupos sociais, bem como se agrega as novas diretrizes curriculares do ensino de Geografia e aos objetivos e as competências previstas no na Base Nacional Comum Curricular (BNCC). Seja nas redes sociais, no lazer ou no ambiente de trabalho, o mapa está presente permitindo ler o mundo em tempo real. Por isso, essa abordagem pode despertar a motivação dos estudantes para o ensino de Geografia, aprofundar as discussões e tornar as aulas de Geografia mais interessantes nos currículos e nas aspirações pessoais dos alunos.

Nesta perspectiva a Cartografia Escolar, enquanto linguagem geográfica,colabora fortemente com as discussões socioambientais e emerge como uma nova fonte de debate que merece atenção e envolvimento dos pesquisadores voltados às metodologias de ensino dessa área do conhecimento, especialmente, no que tange ao ensino híbrido, aos multiletramentos e a multimodalidade.

Assim, no presente artigo, fez-se um esboço teórico sobre a temática multiletramentos e multimodalidade na Cartografia Escolar voltados ao ensino de Geografia. O texto integra a fundamentação teórica da tese desenvolvida no Programa de Pós-graduação em Geografia, da Universidade Federal de Santa Maria (PPGGeo/UFSM), intitulada "Cartografia Escolar, multimodalidade e multiletramentos para 0 ensino de Geografia na contemporaneidade". O trabalho está registrado no sob o no 042386 no

ParaOnde!?, Porto Alegre, v.12 n.2, p.01-10, 2019.http://seer.ufrgs.br/paraonde Edição Especial - III Colóquio de Pesquisadores em Geografia Física Ensino de Geografia 


\section{Multimodalidade e multiletramentos na cartografia escolar para o ensino de geografia}

Ao refletir sobre a Cartografia Escolar para o ensino de Geografia contemporâneo é preciso pensar essa interface a partir de novas formas de ensinar e de aprender no século XXI. A multimodalidade e os multiletramentos são possibilidades teórico-metodológicas para o ensino de Geografia na atualidade. Assim, para discutir tais conceitos, no contexto da Geografia, necessita-se compreender a vida em sociedade como uma vida fluída e desterritorializada, em a população vive o local e o global ao mesmo tempo. Uma sociedade em que a espacialidade e a informação/conhecimento se veem desafiados pela liquidez das relações e dos modos de vida, bem como pelas inquietações socioambientais que emergem das velozes transformações geradas pelas ações humanas (BAUMAN, 2001).

Neste interim, ressalta-se que, segundo Cope e Kalantzis (2009 e 2015) e Rojo (2012), a multimodalidade perpassa pela simultaneidade de duas ou mais modalidades de comunicação em um recurso ou objeto de análise e é uma característica essencial dos multiletramentos. Já os multiletramentos, que estão fortemente ligados ao conceito de cidadania, o qual é essencial à discussão socioambiental, e diferem do já conhecido letramento por adotarem a multimodalidade e o designe como foco de análise.

O conceito de multiletramentos, então, foi proposto pelos pesquisadores que integram o grupo autodenominado Nova Londres e compreende dois entendimentos básicos: "por um lado à multiplicidade de linguagens, semioses e mídias envolvidas na criação de significação para os textos multimodais contemporâneos e por outro, para a pluralidade e a diversidade cultural trazidas pelos autores-leitores contemporâneos a essa criação de significação" (ROJO, 2013, p.14).

Logo:

No que se refere à multiplicidade de culturas, é preciso notar: [...] que os textos que hoje vemos a nossa volta são produções culturais letradas em efetiva circulação social, como um conjunto de textos híbridos de diferentes letramentos (vernáculas e dominantes), de diferentes campos (ditos "populares/de massa/eruditos"), desde sempre, híbridos, caracterizados por um processo de escolha pessoal e política e de hibridização de produções de diferentes "coleções" (ROJO, 2012, p. 13).

Já no que tange à multiplicidade de linguagens, modos ou semioses nos textos/mapas em circulação, refere-se às suas "novas" formas de produção, sistematização e apresentação (ROJO, 2012). Por conseguinte, a pedagogia dos multiletramentos apresenta características fortemente vinculadas às "novas" organizações sociais e, de modo especial, às novas mídias e tecnologias que surgem e diversificam as formas de linguagem, diferenciando-as em múltiplas linguagens, que permitem o uso dos mapas como fonte de entendimento do mundo e aliam-se as novas formas de ensinar

ParaOnde!?, Porto Alegre, v.12 n.2, p.01-10, 2019.http://seer.ufrgs.br/paraonde Edição Especial - III Colóquio de Pesquisadores em Geografia Física Ensino de Geografia 
Geografia. Desse modo, aproximam-se da tão buscada Geografia Escolar Crítica, mas que precisa ir além da crítica. Vive-se o momento de propor alternativas para os novos contextos de vida e de vivências. A Geografia precisa propor, fazer e vivenciar, pois está por toda a parte. Viver é fazer Geografia!

$\mathrm{Na}$ sua proposição, o grupo Nova Londres buscou responder basicamente três aspectos da necessidade nessa nova pedagogia: "o por quê", "o que" e "como", visto que se o mundo está mudando, é necessário que o ensino-aprendizagem também mude. Cope e Kalantzis (2009, p. 168) apontam que "Educationisoneofthekeysourcesof social equity", neste sentido, uma nova forma de ensinar pode dar mais acesso as pessoas e questionar as disparidades existentes na sociedade atual, bem como compreender e tencionar a problemática ambiental contemporânea.

Além disso, ao destacar no sentido de cidadania que envolve a educação e os multiletramentos os pesquisadores destacam que:

[...] Either way, the old literacy is no longer adequate either to support decentralized governance along neoliberal lines or a civil society capable of making reasonable demands of its state. The multiliteracies approach suggests a pedagogy for active citizenship, centred on learners as agents in their own knowledge processes, capable of contributing their own as well as negotiating the differences between one community and the next. [...] Perhaps even more central to the case for multiliteracies today is the changing nature of everyday life itself over the past decade. We are in the midst of a profound shift in the balance of agency, in which as workers, citizens and persons we are more and more required to be users, players, creators and discerning consumers rather than the spectators, delegates, audiences or quiescente consumers of an earlier modernity. Albeit in fits and starts, the command society is being displaced by the society of reflexivity". (COPE, KALANTZIS, 2009, p. 172-173).

No que tange as motivações e definições da proposição dessa pedagogia, tem-se a necessidade de articular os anseios dos trabalhadores e dos cidadãos, ou seja, das pessoas em geral com as novas formas de relações sociais pautadas pelas novas linguagens, mídias e semioses. Assim, "[...]In a pedagogy of multiliteracies, all forms of representation, including language,should be regarded as dynamic processes of transformation rather than processes of reproduction [...]" (COPE; KALANTZIS, 2009, p. 172-173), gerando a autonomia dos indivíduos em suas atuações em sociedade e na sua compreensão dos espaços vividos ou ausentes.

Além disso, para se realizar um multiletramento é necessário apontar algumas características importantes:

(a) eles são interativos; mais que isso são colaborativos; (b) eles fraturam e transgridem as relações de poder estabelecidas, em especial, as relações de propriedade (das máquinas, das ferramentas, das ideias, dos textos [verbais ou não]); (c) eles são híbridos, fronteiriços, mestiços (de linguagem, modos, mídias e culturas) (ROJO, 2012, p. 23).

ParaOnde!?, Porto Alegre, v.12 n.2, p.01-10, 2019.http://seer.ufrgs.br/paraonde Edição Especial - III Colóquio de Pesquisadores em Geografia Física Ensino de Geografia 
Isto posto, no mundo contemporâneo, a multimodalidade e os multiletramentos são parte do conjunto integrado de habilidades exigidas para criar e comunicar conhecimentos. $E$, nesta perspectiva, os mapas podem ser recursos multimodais e híbridos que permitem buscar informações em múltiplas representações e se constituem como excelentes instrumentos de aprendizagem para a pluralidade e a diversidade cultural, natural e multiletrada. Um mapa híbrido e multimodal pode ser conceituado como aquele que é composto por materializações e por relações, demonstrando suas intencionalidades e as múltiplas possibilidades de leituras de mundo de acordo com os interesses e conhecimentos dos estudantes-autores que processam, modificam e adaptam os bancos de dados cartográficos, remixam informações geográficas, sistematizam a produção cartográfica e a compartilham em distintos meios de comunicação através do uso da multimodalidade empregada em sua apresentação e em sua confecção (BATISTA, 2019). Assim, entende-se que o mapa híbrido e multimodal considera a liquidez e a fluidez do espaço geográfico e das relações que nele estão presentes e que isso colabora com o ensino de Geografia mediante a libertação do mapa da "camisa de força" e sua integração enquanto linguagem múltipla e cotidiana da contemporaneidade.

Frente à nova realidade midiática da sociedade do século $\mathrm{XXI}$, "o professor de Geografia (e outros) não detém mais o sacrossanto, o conhecimento, visto serem as diferentes linguagens e as novas tecnologias as detentoras do sagrado social hodierno o virtual" (SOARES, 2003, p. 95). O professor passa a interagir com uma gama de realidades cada vez mais distinta. Assim, a escola necessita diversificar as formas de abordagens para atender as demandas da sociedade atual. Entre essas abordagens e linguagens geográficas, a Cartografia Escolar é essencial ao entendimento dessa nova sociedade a partir dos mapas e dos aplicativos de localização e de realidade virtual instantânea.

Assim, a Cartografia que sempre foi uma grande aliada da Geografia, torna-se ainda mais importante ao ensino e a aprendizagem dessa disciplina. Ela motiva. Ela dinamiza. Ela produz novas leituras de mundo. Ela permite diversificar o olhar sobre as realidades socioambientais do Planeta Terra. Se bem utilizada, permite desenvolver um pensamento espacial capaz de conduzir a leituras críticas da realidade em que se vive e aproximar as leituras temporais e espaciais do cotidiano dos estudantes, fazendo-os se motivarem e desejarem aprender Geografia.

Dessa forma, os multiletramentos são a manifestação educacional da fluidez da sociedade contemporânea, porém com uma característica clara de retomar o pensamento complexo e crítico sobre o espaço, o tempo, a sociedade e a natureza, contribuindo com a formação cidadã dos estudantes. A multimodalidade funciona, então, como um atrativo ao estudo e a dinamização dos saberes e os multiletramentos como a pedagogia norteadora desta concepção.

No que tange a Cartografia propriamente dita, outrora o mapa (tradicional ou analógico) era produzido por um único indivíduo desde a coleta de dados até a arte final. Há relatos, inclusive, de que muitos cartógrafos eram mortos após produzir seus mapeamentos para que quem não possuísse o recurso desconhecesse a área mapeada e para que o mapa não pudesse ser reproduzido. Portanto, não ocorria o processo colaborativo e a informação era propriedade de determinados grupos, não podia ser

ParaOnde!?, Porto Alegre, v.12 n.2, p.01-10, 2019.http://seer.ufrgs.br/paraonde Edição Especial - III Colóquio de Pesquisadores em Geografia Física Ensino de Geografia 
transgredida, fato que é totalmente inverso aos mapeamentos contemporâneos (BATISTA; BECKER; CASSOL, 2018).

$\mathrm{Na}$ atualidade, a facilidade e a instantaneidade na informação representada no mapa é uma excelente forma de comunicação, de localização e de orientação no mundo glocal (o local somado ao global). Gracioli (2017, p. 43) reforça essas ideias em sua pesquisa, mostrando que "[...] alguns programas se destacam como propulsores na interação da cartografia e tecnologias, como a plataforma do Google maps, responsável pela informação de diferentes linguagens (visuais e não visuais) transmitidas ao redor do mundo".

Segundo o pesquisador, a revolução tecnológica, inevitavelmente, provocou mudanças em diferentes setores sociais, proporcionando a necessidade de transformações significativas nas formas de ler e de ensinar pelos mapas contemporâneos na escola do século XXI. "O contato dos estudantes com os meios de comunicação e as informações tornou-se instantâneo e ágil. Dentre as transformações na relação tecnologia e escola, tem-se a (re)formulação estrutural dos textos e os novos modos de ler e produzir conhecimentos" (GRACIOLI, 2017, p. 43), o que faz emergir a necessidade de pensar os multiletramentos na Cartografia Escolar para o ensino de Geografia.

Assim, a escola necessita repensar a inserção deste tão importante recurso no contexto de educação geográfica, superando seu uso como recurso meramente localizacional e passando a interpretá-lo como uma forma de comunicação multimodal, recuperando a análise do lugar, seu ambiente natural e, especialmente, as relações sociais e culturais de sua comunidade. Nesse sentido, as múltiplas possibilidades existentes permitem que a Cartografia, por meio de um elemento essencial (o mapa), insira-se nos meios analógicos (mapas mentais, plantas, cartas, mapas geográficos) e digitais (multimídias, hipermídias, SIGs, animações cartográficas), tornando-se um recurso multimodal que precisa de multiletramentos para ser compreendido em sua essência (BATISTA; BECKER; CASSOL, 2018).

O mapa hoje transgride as noções de propriedade e podem ser (re)produzidos, remixados, adaptados, reconstruídos por diferentes autores e de diferentes formas ao combinar tecnologias distintas como o Sistema de Informações Geográficas (SIGs), a Aerofotogrametria, o Sistema de Aeronaves Remotamente Pilotadas (como os Drones e os Vants), o Sensoriamento Remoto, o Sistema Global de Navegação por Satélite (GNSS) e o Geoprocessamento. Assim, os mapas digitais integram uma nova forma de representar e de compreender o mundo, exigindo multiletramentos, processos de criação colaborativa e ensino híbrido, visto que quem o produz o mapa quase sempre não é a mesma pessoa que produz a base de dados, geralmente, extraída de diferentes bancos de dados geográficos (BATISTA; BECKER; CASSOL, 2018).

Logo, o processo de construção colaborativo do mapa se insere em um novo contexto de diversidade cultural que valoriza as criações conjugadas e participativas, possibilitando o estudo das temáticas físico-naturais e sociais em diferentes escalas. Assim, a tecnologia tornou o mapa estritamente associado às (Geo)Tecnologias e, por consequência, aproximou-o das discussões que emergem da pedagogia dos multiletramentos. A coleta, o armazenamento, a recuperação, o processamento, a análise e a síntese dos dados, permitem que a representação seja capaz de revelar informações

ParaOnde!?, Porto Alegre, v.12 n.2, p.01-10, 2019.http://seer.ufrgs.br/paraonde Edição Especial - III Colóquio de Pesquisadores em Geografia Física Ensino de Geografia 
sobre lugares ao longo do tempo e que ela seja sistematizada por diferentes autoresleitores (MARTINELLI, 2009).

Dionísio e Leite (2015) ressaltam no Caderno de Sugestões Didáticas, voltado ao ensino de Letras, toda a diversidade dos mapas no atual contexto, trazendo associação do mapa com videoclipes, Google Maps, Pinturas, Tatuagens e Estamparias (o mapa fora do mapa), Atlas e Tirinhas. O Hipermapa do Município de Quevedos (RS), produzido por Batista (2015), é um exemplo de recurso multimodal e híbrido porque atrela mapas, fotografias, animações, textos escritos o estudo da realidade ambiental local, através da Cartografia Escolar, trabalhando com múltiplas possibilidades e caminhos de leitura das informações.

Dessa forma, o mapa, hoje, insere-se no contexto das múltiplas linguagensexigindo um novo olhar sobre essa forma de representação e abrindo perspectivas de ensino e de pesquisa que versem sobre a pedagogia dos multiletramentos no ensino de Geografia. Essa ideia é reforçada por Canto (2016, p. 755) quando afirma que "os mapas se desmaterializaram, passaram não apenas a serem produzidos por meio de computadores, como também são feitos para circularem no espaço das redes" (CANTO, 2016, p. 755) e isso possibilita a diversificação dos mapeamentos e a inovação pedagógica em sala de aula.

Como menciona Canto (2016), os mapas estão constantemente se transformando o que abre espaço para múltiplas abordagens sobre eles e, consequentemente, os tornam um campo de pesquisa em expansão, especialmente, no que tange a multimodalidade e aos multiletramentos no ensino de Geografia. Os multiletramentos na Cartografia Escolar são parte de um conjunto integrado de habilidades que o cidadão contemporâneo, da sociedade fluída, necessita para: reconhecer suas necessidades; localizar e avaliar a qualidade da informação; armazenar e recuperar informações; fazer uso efetivo e ético das informações; e aplicar a informação para criar e comunicar conhecimentos.

No que tange especificamente ao estudo de temáticas da Geografia Física elencamos a possibilidade de realizar mapeamentos e análises articulando diferentes softwares livres. No caso tese, os estudantes de Ensino Fundamental e do Ensino Médio realizaram mapeamentos colaborativos e multimodais com o software livre QGIS e após os analisaram construindo um site ${ }^{1}$ colaborativo entre as duas escolas participantes da pesquisa, a saber: Escola Municipal de Ensino Fundamental Junto ao CAIC Luizinho de Grandi e Colégio Tiradentes da Brigada Militar. A proposta permitiu articular diferente olhares sobre a área urbana de Santa Maria/RS e potencializou a colaboração (mediada pela pesquisadora e pelas tecnologias) entre grupos que não se conhecem pessoalmente, mas que aprenderam sobre o meio onde vivem em colaboração (BATISTA, 2019).

Entre os mapeamentos realizados destacamos os mapas de Uso e Ocupação da Terra/do Solo, Mapa hidrográfico da área urbana de Santa Maria/RS e Mapa de Altitudes da área urbana de Santa Maria/RS (debatendo conceitos como curvas de nível e pontos cotados). Além disso, os estudantes analisaram as formas de relevo com auxílio da visualização 3D (Superfície) do Google Earth e perfis topográficos da área urbana no mesmo software, bem como debateram conceitos de climatologia e sequências de tempo

\footnotetext{
${ }^{1}$ Disponível em <https://tesecartoescolar20.wixsite.com/metodologia >. Acesso em outubro de 2018.
}

ParaOnde!?, Porto Alegre, v.12 n.2, p.01-10, 2019.http://seer.ufrgs.br/paraonde Edição Especial - III Colóquio de Pesquisadores em Geografia Física Ensino de Geografia 
atmosférico observado através Windy e de anotações sobre o que observavam no cotidiano.

Essa integração entre múltiplos autores e coautores na produção dos elementos que compõem o site e do próprio site aliada a diferentes softwares livres estimulou a compreensão das características físicas (e sociais) da área urbana do município em que os alunos estudam e demostrou que a aprendizagem mediada pelos mapas híbridos e multimodais pode enriquecer os debates de multiletramento para o ensino de Geografia, articulando ferramentas didáticas e linguagens na discussão dessa disciplina. Evidenciouse que a compreensão das características físicas, permeadas pelo meio natural em relação à ocupação antrópica, tornou-se mais rica e abrangente em ambas as turmas de aplicação e comprovou-se a eficácia das práticas colaborativas e multimodais e dos multiletramentos para o ensino de Geografia.

Assim, ressalta-se que mais do que nunca, emerge a discussão das múltiplas linguagens e, em especial, da multimodalidade e dos multiletramentos na Cartografia Escolar para o ensino de Geografia como um campo de investigação e de qualificação da Educação Básica, que precisa ser explorado e debatido enquanto possibilidade teórica e metodológica. "Em um mundo tão dinâmico, de múltiplas linguagens, telas, grupos e culturas, cada um de nós precisa - junto com todas as interações sociais - encontrar tempo para aprofundar, refletir, reelaborar, produzir, fazer novas sínteses" (MORAN, 2015, p. 33) e buscar compreender esse novo contexto socioambiental e cultural emergente como possibilidade de dinamizar e de aprofundar a construção de conhecimentos geográficos.

\section{Conclusão}

Com base no exposto, pressupõe-se que os mapas contemporâneos estão fortemente atrelados aos pressupostos da multimodalidade e da pedagogia dos multiletramentos, pois se inserem na perspectiva da múltipla autoria ou coautoria, da aprendizagem colaborativa, do ensino híbrido e das produções compartilhadas (que fraturam as clássicas relações de poder e de propriedade), sem, no entanto, romper com a necessidade de compreender as territorialidades do glocal e de enfrentar os desafios socioambientais em voga. Logo, tais características presentes na Cartografia Escolar corroboram com a imprescindibilidade de pensar os multiletramentos e a multimodalidade nas práticas pedagógicas para o ensino de Geografia do século XXI .

Portanto, conclui-se que o ensino de Geografia e a Cartografia Escolar se vêm desfiados a compreender e a investigar essas novas formas de representar e de entender o mundo que se configuram no contexto socioambiental contemporâneo. Para isso, as aulas de Geografia devem trabalhar a representação do espaço geográfico de modo articulado com as múltiplas linguagens, tecnologias e mídias emergentes nos contextos ambiental, social, político, econômico, multicultural que hoje integra a vida em sociedade (BATISTA; BECKER; CASSOL, 2018).

ParaOnde!?, Porto Alegre, v.12 n.2, p.01-10, 2019.http://seer.ufrgs.br/paraonde Edição Especial - III Colóquio de Pesquisadores em Geografia Física Ensino de Geografia 


\section{Referências}

BATISTA, N. L. Cartografia Escolar, Multimodalidade e Multiletramentos para o ensino de Geografia na Contemporaneidade. $181 \mathrm{f}$. (Tese de Doutorado/Programa de Pós-Graduação em Geografia). Centro de Ciências Naturais e Exatas (CCNE), Universidade Federal de Santa Maria, Santa Maria/RS, 2019.

BATISTA, N. L; BECKER, E. L. S; CASSOL, R. Mapas híbridos e multimodais: em busca de multiletramentos na Cartografia Escolar. In: Pesquisar - Revista de Estudos e Pesquisas em Ensino de Geografia, v. 5, p. 19-35, 2018.

BATISTA, N. L. A Cartografia Escolar no processo de ensino-aprendizagem: o Hipermapa e sua utilização na Educação Ambiental, em Quevedos/RS. 139 f. (Dissertação de Mestrado/ Programa de Pós-Graduação em Geografia). Centro de Ciências Naturais e Exatas (CCNE), Universidade Federal de Santa Maria, Santa Maria/RS, 2015.

BAUMAN, Z. Modernidade líquida. Rio de Janeiro: Jorge Zahar, 2001.

CANTO, T. S. O mapa como linguagem líquida: novas possibilidades para a Cartografia Escolar In: IX Colóquio de Cartografia para Crianças e Escolares, 2016, Goiânia. Anais.Goiânia: UFG, 2016. v. 1. p. 753-759.

COPE, B; KALANTZIS, M. Multiliteracies: New Literacies, New Learning. In: Pedagogies: An International Journal, Vol. 4, 2009, p. 164-195.

COPE, B; KALANTZIS, M. The Things You Do to Know: An Introduction to the Pedagogy of Multiliteracies. In: COPE, B; KALANTZIS, M. A Pedagogy of Multiliteracies: Learning By Design. London: Palgrave, 2015.

DIONÍSIO, A. P; LEITE, S. Mapas (Série Cadernos de Sugestão Didáticas). Recife: Pipa Comunicações, 2015.

GRACIOLI, J. M. A. Multiletramentos e leitura de mapas no ensino de Geografia.103 f. (Dissertação de Mestrado/Programa de Pós-graduação em Educação). Universidade Federal do Triângulo Mineiro, Uberaba, MG, 2017.

MARTINELLI, M. Mapas, gráficos e redes. São Paulo: Oficina de Textos, 2009.

MORAN, J. Educação híbrida. Um conceito-chave para a educação, hoje. In: BACICH, L; NETO TANZIN, A; TREVISANI, F. M. Ensino Híbrido: personalização e tecnologia da educação. Porto Alegre: Penso, 2015.

ROJO, R. H. R. Letramentos múltiplos, escola e inclusão social. São Paulo: Parábola Editoral, 2009.

ROJO, R. H. R. (Org.). Multiletramentos na escola. São Paulo: Parábola, 2012.

ParaOnde!?, Porto Alegre, v.12 n.2, p.01-10, 2019.http://seer.ufrgs.br/paraonde Edição Especial - III Colóquio de Pesquisadores em Geografia Física Ensino de Geografia 
ROJO, R. H. R. Gêneros discursivos do Círculo de Bakhtin e multiletramentos. In:

ROJO, R. H. R. (Org.). Escola conectada: os multiletramentos e as TICs. São Paulo:

Parábola, 2013. p. $13-36$.

SOARES, M. L. A. Práticas de ensino para uma sociedade imagética: diferentes linguagens e novas tecnologias. In: Geografares, Vitória, oํ 4, 2003. 